\title{
Lactato de sódio, nisina e sua combinação na validade comercial da linguiça Toscana embalada a vácuo e estocada a $4^{\circ} \mathrm{C}$
}

\author{
Sodium lactate, nisin and their combination in the shelf life of pork sausage \\ vacuum packed and stored at $4^{\circ} \mathrm{C}$
}

\author{
Rafael Xavier Araújo Silva ${ }^{\mathrm{I}}$ Kelly Fernanda Campos José ${ }^{\mathrm{III}}$ Robson Maia Franco ${ }^{\mathrm{II}}$ \\ Teófilo José Pimentel da Silva ${ }^{\text {II }}$
}

\section{RESUMO}

Objetivou-se, neste estudo, avaliar a validade comercial de quatro formulações de linguiça toscana (Controle sem adição de aditivo, F1 - adicionada de 3\% de lactato de sódio, F2 - adicionada de 0,5\% de nisina e F3 - adicionada de 3\% de lactato de sódio e 0,5\% de nisina). As amostras foram distribuídas em sacos de polietileno contendo 200 gramas para cada formulação e dia de estocagem, para posteriores análises bacteriológicas e físico-químicas. Todas as formulações foram embaladas a vácuo e mantidas sob refrigeração a temperatura de $4^{\circ} \mathrm{C}$. Em relação à validade comercial, as amostras foram submetidas às seguintes análises bacteriológicas: contagem de bactérias heterotróficas aeróbias mesófilas e psicrotróficas; contagem de bactérias ácido-láticas e contagem de enterobactérias. As análises fisicoquímicas realizadas foram: $\mathrm{pH}$, atividade de água e teor de substância reativa ao ácido tiobarbitúrico. Interpretando-se os resultados obtidos no experimento, concluiu-se que a utilização da combinação de 3\% de lactato de sódio e 0,5\% de nisina, aumentou a validade das amostras, quando comparada às demais.

Palavras-chave: antimicrobiano natural, bacteriocina, estocagem e embutido de carne de porco.

\section{ABSTRACT}

The aim of this study was to evaluate the shelf life of four commercial formulations pork sausage (Control - no added additive, F1 - added 3\% sodium lactate, F2 - added 0.5\% nisin and F3 - added $3 \%$ sodium lactate and $0.5 \%$ nisin). The samples were distributed into polyethylene bags containing 200 grams for each day of storage and formulation for subsequent bacteriological and physicochemical analysis. All formulations were vacuum packed and stored at $4^{\circ} \mathrm{C}$. Regarding the shelf life samples were submitted to the following bacteriological counts of heterotrophic bacteria aerobic mesophilic and psychrotrophic; count of lactic acid bacteria count and Enterobacteriaceae. The analyzes were carried out physico-chemical: $\mathrm{pH}$, water activity and the content of thiobarbituric acid reactive substance. Interpreting the results obtained in the experiment it was concluded that the use of a combination of $3 \%$ sodium lactate and $0.5 \%$ nisin increased the shelf life compared to other samples.

Key words: natural antimicrobial, bacteriocin, storage and pork sausage filling.

\section{INTRODUÇÃO}

O uso da carne suína na alimentação humana, seja no preparo de cortes in natura ou na fabricação de um grande número de embutidos, salgados e defumados, deverá atingir, ao longo dos próximos anos, um crescimento na sua produção e consumo, com taxas de 2,84\% e 1,79\%, respectivamente, até 2019 (BRASIL, 2013). Dentre os embutidos, a linguiça se sobressai como uma das mais produzidas. Tal fato pode ser justificado pela sua produção não exigir tecnologia sofisticada, utilizar poucos aparelhos e estes serem de baixo custo (MILANI, et al., 2003).

$\mathrm{O}$ uso de substâncias naturais e reconhecidamente seguras Generally Recognized As Safe (GRAS) tem sido empregado na indústria cárnea para aumentar a validade comercial dos produtos e manter ou melhorar as características sensoriais destes (WANG, 2000). Nesse âmbito, o uso do lactato de

IPrograma de Pós-graduação em Higiene Veterinária e Processamento Tecnológico de Produtos de Origem Animal, Faculdade de Veterinária, Universidade Federal Fluminense (UFF), Rua Vital Brasil Filho, 64, 24230-340, Niterói, RJ, Brasil. E-mail: rafa_wise@yahoo.com.br. Autor para correspondência.

IIDepartamento de Tecnologia de Alimentos, Faculdade de Veterinária, UFF, Niterói, RJ, Brasil.

IIIDepartamento de Bromatologia, Faculdade de Farmácia, UFF, Niterói, RJ, Brasil. 
sódio, um sal natural com função de acidificação do meio intracelular dos microrganismos e consequente diminuição da sua atividade metabólica, além de permitir a redução da atividade de água, tem sido empregado com função antimicrobiana. Assim como a nisina, uma bacteriocina produzida por Lactococcus lactis subsp. Lactis, que atua formado um poro na membrana citoplasmática e consequentemente ocasionando a lise celular dos microrganismos. Ambos vêm sendo utilizados no controle do crescimento de certas bactérias e, ao mesmo tempo, não afetam negativamente às características sensoriais do produto (SAMELIS et al., 2005).

Nesse sentido, o objetivo deste estudo foi conduzir a avaliação do efeito do lactato de sódio, nisina e sua combinação na validade comercial da linguiça Toscana através da avaliação bacteriológica (contagem de bactérias mesófilas, psicrotróficas, bactérias ácido-láticas e enterobacteriáceas) e físicoquímica ( $\mathrm{pH}$, atividade de água e teor das substâncias reativas ao ácido tiobarbitúrico), nos diferentes períodos de estocagem, além de definir qual amostra obteve melhor desempenho sob o ponto de vista bacteriológico e fisico-químico.

\section{MATERIAL E MÉTODOS}

A matéria-prima utilizada para a fabricação das linguiças foi obtida em indústria localizada no Vale do Piranga S/A, no estado de Minas Gerais, tendo sido transportada congelada a $-18^{\circ} \mathrm{C}$ em sacos plásticos de polietileno a vácuo até o local de análise. Para elaboração das linguiças Toscana, o experimento baseou-se em três formulações teste e uma formulação controle: Controle: sem presença de lactato de sódio e nisina, F1: adicionada de 3\% de lactato de sódio (60\% p/v), F2: adicionada de $0,5 \%$ de nisina (2,5\% p/p) e F3: combinando a adição de $3 \%$ de lactato de sódio $(60 \% \mathrm{p} / \mathrm{v})$ com $0,5 \%$ de nisina $(2,5 \% \mathrm{p} / \mathrm{p})$.

As carnes e o toucinho foram cortados manualmente com auxílio de facas de aço inoxidável (uma para cada matéria-prima), em forma de cubos de tamanhos irregulares. Os cubos foram cominuídos individualmente em máquina moedora, modelo MCR 10, da marca G.Paniz, com disco de $1 \mathrm{~cm}$. Em seguida, foi realizada a mistura, de forma manual, do toucinho com a carne, para posteriormente serem adicionados os demais ingredientes da formulação e os aditivos utilizados no experimento. O embutimento das linguiças com tripa natural de suíno foi realizado de forma manual, utilizando para tal, a embutideira horizontal, modelo EJ-08, da marca Jamar. Cada gomo foi padronizado para ter em média $15 \mathrm{~cm}$ de comprimento e pesar aproximadamente 100 gramas. As linguiças foram identificadas com suas respectivas formulações em sacos de polietileno, embaladas a vácuo e acondicionadas em temperatura de $\pm 4^{\circ} \mathrm{C}$.

As análises bacteriológicas foram realizadas em duplicata no $1^{\circ}, 5^{\circ}, 1^{\circ}, 15^{\circ}, 20^{\circ}$, $25^{\circ}, 30^{\circ}, 35^{\circ}$ e $40^{\circ}$ dias. A Contagem de Bactérias Heterotróficas Aeróbias Mesófilas (CBHAM), Contagem de Bactérias Ácido-Láticas (BAL) e contagem de Enterobacteriaceas foram realizadas conforme a Instrução Normativa ${ }^{\circ} 62$, de 26 de agosto de 2003 (BRASIL, 2003), e a Contagem de Bactérias Heterotróficas Aeróbias Psicrotróficas foi realizada conforme a American Public Health Association (APHA, 2001). Para confirmação das colônias suspeitas de Enterobacteriacea, após incubação a 35$37^{\circ} \mathrm{C}$, por 24 horas, foi realizada a prova da oxidase por repique em ágar estoque inclinado, incubado a $35-37^{\circ} \mathrm{C}$, por 24 horas. Para CBHAM e CBHAP, a incubação foi feita a $36 \pm 1^{\circ} \mathrm{C}$ por 48 horas e a $4 \pm 1^{\circ} \mathrm{C}$ por dez dias, respectivamente. As bactérias ácidoláticas foram incubadas a $35-37^{\circ} \mathrm{C}$ por 48 horas. Após esses procedimentos, foi realizada a prova da catalase e observação das características morfo-tintoriais para a confirmação.

A análise de $\mathrm{pH}$ foi realizada em triplicata no $1^{\circ}, 5^{\circ}, 10^{\circ}, 15^{\circ}, 20^{\circ}, 25^{\circ}, 30^{\circ}, 35^{\circ}$ e $40^{\circ}$ dias, utilizando a metodologia descrita na Instrução Normativa n $^{\circ} 20$ de 21 de julho de 1999 (BRASIL, 1999). A análise de Substância Reativa ao Ácido Tiobarbitúrico (TBARS) foi realizada em duplicata no $1^{\circ}, 7^{\circ}, 14^{\circ}, 21^{\circ}, 28^{\circ}, 35^{\circ}$ e $42^{\circ}$ dias, seguindo a metodologia descrita por TARLADGIS et al. (1960). A determinação da Atividade de água (Aa) foi realizada em triplicata no $1^{\circ}, 7^{\circ}, 14^{\circ}, 21^{\circ}, 28^{\circ}, 35^{\circ}$ e $42^{\circ}$ dias, seguindo as instruções que acompanham o aparelho de Atividade de Água (Aw43 - ETEC). O aparelho foi calibrado à temperatura de $20^{\circ} \mathrm{C}$, sendo a inserção direta das amostras em cápsulas próprias do equipamento.

Para a estatística dos dados bacteriológicos e físico-químicos, foi realizada análise de variância (ANOVA), com nível de significância de 5\% $(\mathrm{P}<0,05)$ e em modelo inteiramente casualizado. Para comparação entre as médias, foi utilizado o teste de Tukey. Para todos os cálculos, foi utilizado o programa XLSTAT Pro software, versão 2013.

\section{RESULTADOS E DISCUSSÃO}

Os resultados da Contagem de Bactérias Heterotróficas Aeróbias Mesófilas (CBHAM), durante o período de estocagem, podem ser 
evidenciados na tabela 1. Para as três formulações (F1, F2 e F3), foram encontrados valores iniciais inferiores a $5 \log _{10}$ UFC $\mathrm{g}^{-1}$. Ambas as amostras, Controle no $30^{\circ}$ dia e F2 no $25^{\circ}$ dia, alcançaram o valor de $7 \log _{10}$ UFC $\mathrm{g}^{-1}$, apresentando perda da qualidade da matriz alimentar sob o ponto de vista microbiológico, segundo International Commission on Microbiological Specifications for Foods (ICMSF, 1988). As formulações F1 e F3 apresentaram as menores contagens ao longo do período de estocagem e não alcançaram valores iguais ou superiores a $7 \log _{10}$ UFC g g ${ }^{-1}$ até o $40^{\circ}$ dia. Esses resultados estão em conformidade com LIN \& LIN (2002), os quais evidenciaram que o uso do lactato de sódio teve um efeito bacteriostático nas amostras tratadas com 3\% de lactato de sódio em linguiças tipo Chinesa, enquanto que BRADLEY et al., (2011) observaram resultados semelhantes na contagem total em meio Ágar Padrão para Contagem (APC) para salsicha do tipo hot-dog.

A representação da Contagem de Bactérias Heterotróficas Aeróbias Psicrotróficas (CBHAP) durante o período de estocagem pode ser evidenciada na tabela 1 . O limite máximo de $7 \log _{10}$ UFC $\mathrm{g}^{-1}$ foi alcançado pelas três amostras no $35^{\circ}$ dia de armazenamento, evidenciando uma menor taxa metabólica dessas bactérias, que crescem em temperatura de refrigeração $\left( \pm 4^{\circ} \mathrm{C}\right)$. Esses resultados são controversos, segundo DELVES-BROUGHTON (2005); MACA (1999), já que o primeiro autor avaliou o efeito de salsichas embaladas a vácuo sob refrigeração e adicionadas de solução de 6,25mg de nisina por litro, sendo constatado o aumento da validade comercial dessas linguiças quando comparadas às amostras controle (sem nisina). O segundo autor observou que a utilização de apenas 3\% de lactato de sódio foi suficiente para aumentar a validade comercial de carne de porco embalada a vácuo sob refrigeração. A formulação F3 diferiu estatisticamente das demais para todos os dias avaliados, apresentando os menores valores em $\log _{10}$ UFC g-1 durante o período de estocagem não alcançando o valor de $7 \log _{10}$ UCF g-1 até o último dia de análise. Resultados semelhantes foram observados por NYKANEN et al. (2000); BUNCIC et al. (1995), em que a associação de bacteriocinas com lactato de sódio ocasionou um decréscimo da contagem bacteriana, quando comparado a adição dos aditivos separadamente.

A CBHAP foi maior quando comparada a CBHAM em todas as amostras, evidenciando uma boa atividade enzimática dos microrganismos psicrotróficos em baixas temperaturas (JAY, 2005). Entretanto, isso não ocorreu na amostra F3, que combina lactato de sódio e nisina, evidenciando assim um sinergismo dos aditivos sobre essas bactérias.

A representação da Contagem de Bactérias Ácido Láticas (BAL) durante o período de estocagem pode ser evidenciada na tabela 2 . O crescimento das bactérias ácido láticas só foi observado a partir do $5^{\circ}$ dia de estocagem, isso pode ser explicado por essas bactérias não estarem adaptadas ao meio, provavelmente, em função da presença de oxigênio residual presente na embalagem a vácuo e/ou injúria celular, devido ao processamento da matriz alimentícia. A amostra F3 foi a que se mostrou mais eficaz, obtendo limite máximo de $4 \log _{10}$ UCF g-1 no $40^{\circ}$ dia. Os resultados evidenciam o sinergismo

Tabela 1 - Valores médios em $\log _{10} \mathrm{UFC} \mathrm{g}^{-1}$ de CBHAM e CBHAP das quatro formulações

\begin{tabular}{|c|c|c|c|c|c|c|c|c|}
\hline \multirow{2}{*}{$\begin{array}{l}\text { Amostras } \\
\text { Dias }\end{array}$} & \multicolumn{4}{|c|}{ - } & \multicolumn{2}{|c|}{----------------F2--------------- } & \multicolumn{2}{|c|}{ 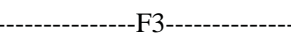 } \\
\hline & СBHAM & СВНАР & СBHAM & СBНAP & СBHAM & СBHAP & СBHAM & СBHAP \\
\hline $1^{\underline{0}}$ & $5.856^{\mathrm{aA}}$ & $5.702^{\mathrm{aA}}$ & $4.796^{\mathrm{bB}}$ & $5.662^{\mathrm{aA}}$ & $4.844^{\mathrm{bB}}$ & $5.426^{\mathrm{bB}}$ & $4.612^{\mathrm{cC}}$ & $4.676^{\mathrm{cC}}$ \\
\hline $5^{0}$ & $5.776^{\mathrm{aA}}$ & $5.774^{\mathrm{aA}}$ & $4.732^{\mathrm{bB}}$ & $5.462^{\mathrm{aA}}$ & $4.492^{\mathrm{bB}}$ & $5.433^{\mathrm{aA}}$ & $4.181^{\mathrm{cC}}$ & $4.437^{\mathrm{bB}}$ \\
\hline $10^{\circ}$ & $6.905^{\mathrm{aA}}$ & $5.851^{\mathrm{aA}}$ & $5.022^{\mathrm{cC}}$ & $5.706^{\mathrm{bB}}$ & $5.825^{\mathrm{bB}}$ & $5.918^{\mathrm{aA}}$ & $4.529^{\mathrm{dD}}$ & $5.570^{\mathrm{cC}}$ \\
\hline $15^{\circ}$ & $6.203^{\mathrm{aA}}$ & $6.948^{\mathrm{aA}}$ & $5.316^{\mathrm{cC}}$ & $5.829^{\mathrm{bB}}$ & $5.902^{\mathrm{abAB}}$ & $4.908^{\mathrm{cC}}$ & $5.571^{\mathrm{bcBC}}$ & $4.783^{\mathrm{dD}}$ \\
\hline $20^{\circ}$ & $6.851^{\mathrm{aA}}$ & $6.838^{\mathrm{aA}}$ & $4.648^{\mathrm{dD}}$ & $6.638^{\mathrm{bB}}$ & $5.979^{\mathrm{bB}}$ & $6.606^{\mathrm{bB}}$ & $5.139^{\mathrm{cC}}$ & $4.581^{\mathrm{cC}}$ \\
\hline $25^{\circ}$ & $6.835^{\mathrm{aA}}$ & $6.655^{\mathrm{aA}}$ & $5.703^{\mathrm{bB}}$ & $5.824^{\mathrm{bB}}$ & $7.192^{\mathrm{aA}}$ & $6.840^{\mathrm{aA}}$ & $4.649^{\mathrm{cC}}$ & $4.263^{\mathrm{cC}}$ \\
\hline $30^{\circ}$ & $7.436^{\mathrm{aA}}$ & $6.759^{\mathrm{aA}}$ & $6.401^{\mathrm{bB}}$ & $6.573^{\mathrm{aA}}$ & $7.835^{\mathrm{aA}}$ & $6.607^{\mathrm{aA}}$ & $5.758^{\mathrm{cC}}$ & $5.277^{\mathrm{bB}}$ \\
\hline $35^{\circ}$ & $7.941^{\mathrm{aA}}$ & $7.947^{\mathrm{aA}}$ & $6.815^{\mathrm{cC}}$ & $7.536^{\mathrm{cC}}$ & $7.838^{\mathrm{aA}}$ & $7.777^{\mathrm{bB}}$ & $5.797^{\mathrm{dD}}$ & $6.694^{\mathrm{dD}}$ \\
\hline $40^{\circ}$ & $8.011^{\mathrm{aA}}$ & $7.990^{\mathrm{aA}}$ & $6.914^{\mathrm{cC}}$ & $7.531^{\mathrm{bB}}$ & $7.983^{\mathrm{aA}}$ & $7.482^{\mathrm{bB}}$ & $6.821^{\mathrm{dD}}$ & $6.774^{\mathrm{cC}}$ \\
\hline
\end{tabular}

*Diferença entre letras minúsculas na mesma coluna indica presença de diferença estatística $(\mathrm{P}<0,05)$ entre os tratamentos (Linguiças). Diferença entre letras maiúsculas na mesma coluna indica presença de diferença estatística $(\mathrm{P}<0,05)$ durante o período de estocagem. $\mathrm{C}$ (sem adição de aditivo); F1 (adição de 3\% lactato de sódio); F2 (adição de 0,5\% de nisina) e F3 (adição de 3\% de lactato de sódio e 0,5\% de nisina). CBHAM - Contagem de Bactérias Heterotróficas Aeróbias Mesófilas. CBHAP - Contagem de Bactérias Heterotróficas Aeróbias Psicrotróficas. 
Tabela 2 - Valores médios em $\log _{10}$ UFC g ${ }^{-1}$ de Bactérias Ácido-Láticas (BAL) e Enterobacteriacea (ENT) das quatro formulações.

\begin{tabular}{|c|c|c|c|c|c|c|c|c|}
\hline \multirow{2}{*}{$\begin{array}{l}\text { Amostras } \\
\text { Dias }\end{array}$} & \multicolumn{4}{|c|}{------C----------------- } & \multicolumn{4}{|c|}{------------------F2------------------ -----------------F3--------------' } \\
\hline & BAL & ENT & BAL & ENT & BAL & ENT & BAL & ENT \\
\hline $1^{\underline{0}}$ & & $1.215^{\mathrm{cC}}$ & & $1.558^{\mathrm{bB}}$ & & $1.772^{\mathrm{aA}}$ & & $1.411^{\mathrm{bcBC}}$ \\
\hline $5^{0}$ & $3.524^{\mathrm{aA}}$ & $2.076^{\mathrm{cC}}$ & $2.370^{\mathrm{cC}}$ & $2.626^{\mathrm{bB}}$ & $2.544^{\mathrm{bB}}$ & $2.579^{\mathrm{bB}}$ & $2.127^{\mathrm{dD}}$ & $2.941^{\mathrm{aA}}$ \\
\hline $10^{\circ}$ & $4.894^{\mathrm{aA}}$ & $3.522^{\mathrm{aA}}$ & $3.127^{\mathrm{cC}}$ & $3.647^{\mathrm{aA}}$ & $4.502^{\mathrm{bB}}$ & $3.628^{\mathrm{aA}}$ & $3.321^{\mathrm{cC}}$ & $2.647^{\mathrm{bB}}$ \\
\hline $15^{\circ}$ & $4.802^{\mathrm{aA}}$ & $3.638^{\mathrm{bB}}$ & $4.207^{\mathrm{bB}}$ & $3.020^{\mathrm{cC}}$ & $4.746^{\mathrm{aA}}$ & $3.115^{\mathrm{cC}}$ & $3.556^{\mathrm{cC}}$ & $3.791^{\mathrm{aA}}$ \\
\hline $20^{\circ}$ & $3.762^{\mathrm{aA}}$ & $3.495^{\mathrm{bB}}$ & $2.444^{\mathrm{cC}}$ & $3.641^{\mathrm{aA}}$ & $3.510^{\mathrm{bB}}$ & $3.491^{\mathrm{bB}}$ & $2.489^{\mathrm{cC}}$ & $2.913^{\mathrm{cC}}$ \\
\hline $25^{\circ}$ & $5.854^{\mathrm{aA}}$ & $3.531^{\mathrm{aA}}$ & $3.484^{\mathrm{cC}}$ & $3.252^{\mathrm{bcBC}}$ & $3.595^{\mathrm{bB}}$ & $3.321^{\mathrm{bB}}$ & $2.612^{\mathrm{dD}}$ & $3.108^{\mathrm{cC}}$ \\
\hline $30^{\circ}$ & $5.921^{\mathrm{aA}}$ & $3.227^{\mathrm{cC}}$ & $5.638^{\mathrm{cC}}$ & $3.702^{\mathrm{aA}}$ & $5.817^{\mathrm{bB}}$ & $3.444^{\mathrm{bB}}$ & $3.378^{\mathrm{dD}}$ & $3.384^{\mathrm{bB}}$ \\
\hline $35^{\circ}$ & $5.819^{\mathrm{aA}}$ & $3.596^{\mathrm{aA}}$ & $4.802^{\mathrm{bB}}$ & $3.504^{\mathrm{aA}}$ & $5.792^{\mathrm{aA}}$ & $3.511^{\mathrm{aA}}$ & $4.608^{\mathrm{cC}}$ & $3.193^{\mathrm{bB}}$ \\
\hline $40^{\circ}$ & $5.735^{\mathrm{aA}}$ & NR & $5.498^{\mathrm{aA}}$ & NR & $5.707^{\mathrm{aA}}$ & NR & $4.627^{\mathrm{bB}}$ & NR \\
\hline
\end{tabular}

*Diferença entre letras minúsculas na mesma coluna indica presença de diferença estatística $(\mathrm{P}<0,05)$ entre os tratamentos $($ Linguiças). Diferença entre letras maiúsculas na mesma coluna indica presença de diferença estatística $(\mathrm{P}<0,05)$ durante o período de estocagem. $\mathrm{C}$ (sem adição de aditivo); F1 (adição de 3\% lactato de sódio); F2 (adição de 0,5\% de nisina) e F3 (adição de 3\% de lactato de sódio e 0,5\% de nisina). - Sem crescimento. NR - Não Realizado.

entre os dois aditivos utilizados (lactato de sódio e nisina), corroborando DEEGAN et al. (2006), que relacionam o efeito da nisina a outros aditivos, visando potencializar seus efeitos antimicrobianos.

Conforme apresentado na tabela 2, a contagem de enterobactérias variou de $1,2 \log _{10}$ UFC g ${ }^{-1}$ a $3,7 \log _{10}$ UFC g-1 , durante todo o período de estocagem. Devido à variação irregular da contagem em $\log _{10}$ UFC $\mathrm{g}^{-1}$, não foi possível determinar efeito significativo dos antimicrobianos sobre as enterobactérias. Conforme relatado por PAPADOPOULOS et al. (2003), tal fato pode ser justificado provavelmente por ser uma família muito heterogênea, e os efeitos observados dependerem da dominância de uma determinada espécie.

Os resultados do $\mathrm{pH}$ durante o período de estocagem podem ser evidenciados na tabela 3. A estabilidade do $\mathrm{pH}$ foi mais evidente nas amostras F1 e F3, em que uma pequena queda foi constatada, a partir do $30^{\circ}$ dia de análise. No entanto, até o último dia de análise, ambas as amostras não apresentaram pH inferior a 5,8, sendo este o limite mínimo ideal preconizado para o consumo de produtos cárneos, segundo os Métodos Analíticos para Controle de Produtos de Origem Animal - LANARA (BRASIL, 1981). Esses resultados foram condizentes com TAN \& SHELEF (2002), já que a adição de $2 \%$ de lactato de sódio em carne moída suína manteve o pH estável durante 7 dias, à temperatura de $4^{\circ} \mathrm{C}$. Resultados semelhantes foram observados por LIN \& LIN (2002) em linguiças de carne suína do tipo Chinesa, embaladas a vácuo e adicionadas de $3 \%$ de lactato de sódio, nas quais o $\mathrm{pH}$ variou de 6,2 a 6,0 durante 4 meses, à temperatura de $4^{\circ} \mathrm{C}$.

Os resultados da Aa durante o período de estocagem podem ser observados na tabela 4 . A atividade de água no primeiro dia de análise variou entre as amostras F1 e F3, que apresentaram as menores taxas 0,952 e 0,955, respectivamente, enquanto as amostras F2 e Controle obtiveram 0,962

Tabela 3 - Valores médios de pH das quatro formulações.

\begin{tabular}{|c|c|c|c|c|c|c|c|c|c|}
\hline Amostras & $1^{-}$ & $5^{0}$ & $10^{\circ}$ & $15^{\circ}$ & $20^{\circ}$ & $25^{\circ}$ & $30^{\circ}$ & $35^{\circ}$ & $40^{\circ}$ \\
\hline $\mathrm{C}$ & $6.07^{\mathrm{aB}}$ & $6.11^{\mathrm{aA}}$ & $6.13^{\mathrm{aA}}$ & $6.10^{\mathrm{abAB}}$ & $6.07^{\mathrm{aA}}$ & $5.85^{\mathrm{bB}}$ & $5.76^{\mathrm{cC}}$ & $5.69^{\mathrm{dD}}$ & $5.66^{\mathrm{dD}}$ \\
\hline $\mathrm{F} 1$ & $6.08^{\mathrm{abAB}}$ & $6.08^{\mathrm{abAB}}$ & $6.10^{\mathrm{abAB}}$ & $6.09^{\mathrm{abAB}}$ & $6.07^{\mathrm{aA}}$ & $6.06^{\mathrm{aA}}$ & $5.94^{\mathrm{bB}}$ & $5.93^{\mathrm{bB}}$ & $5.89^{\mathrm{bB}}$ \\
\hline $\mathrm{F} 2$ & $6.08^{\mathrm{abAB}}$ & $6.10^{\mathrm{abAB}}$ & $6.12^{\mathrm{abAB}}$ & $6.07^{\mathrm{bB}}$ & $5.99^{\mathrm{bB}}$ & $5.88^{\mathrm{bB}}$ & $5.79^{\mathrm{cC}}$ & $5.77^{\mathrm{cC}}$ & $5.70^{\mathrm{cC}}$ \\
\hline F3 & $6.10^{\mathrm{aA}}$ & $6.05^{\mathrm{bB}}$ & $6.07^{\mathrm{bB}}$ & $6.11^{\mathrm{aA}}$ & $6.08^{\mathrm{aA}}$ & $6.05^{\mathrm{aA}}$ & $5.97^{\mathrm{aA}}$ & $5.97^{\mathrm{aA}}$ & $5.91^{\mathrm{aA}}$ \\
\hline
\end{tabular}

*Diferença entre letras minúsculas na mesma coluna indica presença de diferença estatística $(\mathrm{P}<0,05)$ entre os tratamentos $($ Linguiças $)$. Diferença entre letras maiúsculas na mesma coluna indica presença de diferença estatística $(\mathrm{P}<0,05)$ durante o período de estocagem. $\mathrm{C}$ (sem adição de aditivo); F1 (adição de 3\% lactato de sódio); F2 (adição de 0,5\% de nisina); e F3 (adição de 3\% de lactato de sódio e 0,5\% de nisina).

Ciência Rural, v.44, n.4, abr, 2014. 
Tabela 4 - Valores médios em $\log _{10}$ UFC g ${ }^{-1}$ de Aa e TBARS (mg de malonaldeído $\mathrm{kg}^{-1}$ ) das quatro formulações.

\begin{tabular}{|c|c|c|c|c|c|c|c|c|}
\hline \multirow{2}{*}{$\begin{array}{l}\text { Amostras } \\
\text { Dias }\end{array}$} & \multicolumn{2}{|c|}{ 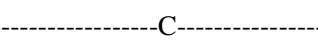 } & \multicolumn{2}{|c|}{-------------'F1--------------- } & \multicolumn{2}{|c|}{-------------F2--------------- } & \multicolumn{2}{|c|}{---------------F3------------ } \\
\hline & Aa & TBARS & Aa & TBARS & $\mathrm{Aa}$ & TBARS & $\mathrm{Aa}$ & TBARS \\
\hline $1^{0}$ & $0.968^{\mathrm{aA}}$ & $0.086^{\mathrm{bB}}$ & $0.952^{\mathrm{dD}}$ & $0.114^{\mathrm{aA}}$ & $0.962^{\mathrm{bB}}$ & $0.074^{\mathrm{cC}}$ & $0.955^{\mathrm{cC}}$ & $0.055^{\mathrm{dD}}$ \\
\hline $7^{0}$ & $0.970^{\mathrm{aA}}$ & $0.611^{\mathrm{aA}}$ & $0.952^{\mathrm{cC}}$ & $0.517^{\mathrm{bB}}$ & $0.962^{\mathrm{bB}}$ & $0.450^{\mathrm{cC}}$ & $0.952^{\mathrm{cC}}$ & $0.175^{\mathrm{dD}}$ \\
\hline $14^{\mathrm{o}}$ & $0.971^{\mathrm{aA}}$ & $0.674^{\mathrm{aA}}$ & $0.951^{\mathrm{cC}}$ & $0.580^{\mathrm{bB}}$ & $0.960^{\mathrm{bB}}$ & $0.571^{\mathrm{cC}}$ & $0.950^{\mathrm{cC}}$ & $0.212^{\mathrm{dD}}$ \\
\hline $21^{\circ}$ & $0.967^{\mathrm{aA}}$ & $0.807^{\mathrm{aA}}$ & $0.950^{\mathrm{dD}}$ & $0.631^{\mathrm{cC}}$ & $0.961^{\text {bB }}$ & $0.701^{\mathrm{bB}}$ & $0.952^{\mathrm{cC}}$ & $0.489^{\mathrm{dD}}$ \\
\hline $28^{0}$ & $0.966^{\mathrm{aA}}$ & $1.041^{\mathrm{aA}}$ & $0.950^{\mathrm{dD}}$ & $0.853^{\mathrm{bB}}$ & $0.959^{\mathrm{bB}}$ & $0.905^{\mathrm{cC}}$ & $0.952^{\mathrm{cC}}$ & $0.598^{\mathrm{dD}}$ \\
\hline $35^{\circ}$ & $0.966^{\mathrm{aA}}$ & $1.382^{\mathrm{aA}}$ & $0.954^{\mathrm{CC}}$ & $1.213^{\mathrm{bB}}$ & $0.961^{\mathrm{bB}}$ & $1.230^{\mathrm{bB}}$ & $0.953^{\mathrm{cC}}$ & $0.802^{\mathrm{cC}}$ \\
\hline $42^{\underline{0}}$ & $0.965^{\mathrm{aA}}$ & $1.745^{\mathrm{aA}}$ & $0.952^{\mathrm{cC}}$ & $1.427^{\mathrm{bB}}$ & $0.961^{\mathrm{bB}}$ & $1.552^{\mathrm{CC}}$ & $0.951^{\mathrm{cC}}$ & $1.062^{\mathrm{dD}}$ \\
\hline
\end{tabular}

*Diferença entre letras minúsculas na mesma coluna indica presença de diferença estatística $(\mathrm{P}<0,05)$ entre os tratamentos (Linguiças) Diferença entre letras maiúsculas na mesma coluna indica presença de diferença estatística $(\mathrm{P}<0,05)$ durante o período de estocagem. $\mathrm{C}$ (sem adição de aditivo); F1 (adição de 3\% lactato de sódio); F2 (adição de 0,5\% de nisina) e F3 (adição de 3\% de lactato de sódio e 0,5\% de nisina). Aa - Atividade de água. TBARS - Teor de Substância Reativa ao Ácido Tiobarbitúrico.

e 0,968 , respectivamente. Esse comportamento permaneceu ao longo dos 42 dias de análise. Esses resultados estão condizentes com dados evidenciados por HOUSTMA et al. (1993) que constataram redução da Aa como um dos possíveis efeitos da atividade antimicrobiana do lactato de sódio nos alimentos.

Os resultados do TBARS durante o período de estocagem estão dispostos na tabela 4. Nos valores de TBARS, foram encontradas diferenças estatísticas para todos os dias analisados, exceto no $35^{\circ}$ dia, nas formulações $\mathrm{F} 1$ e F2, que obtiveram o $\mathrm{P}<0,05$. Todavia, a amostra F3 obteve uma menor taxa de oxidação lipídica até o $42^{\circ}$ dia de análise, indicando que a associação dos dois aditivos (nisina e lactato de sódio) foi mais eficaz na redução do processo oxidativo. Alguns estudos relacionados à adição de lactato de sódio e seu efeito como antioxidante foram realizados por MACA et al. (1999); SALLAM (2007), os quais constataram que a adição de lactato de sódio foi capaz de promover um retardo da oxidação lipídica em produtos cárneos, em nível de TBARS.

\section{CONCLUSÃO}

Sob o ponto de vista bacteriológico e físico-químico, a adição de 3\% de lactato de sódio e 0,5\% de nisina (F3) foi responsável pelos melhores resultados, aumentando em pelo menos cinco dias a validade comercial da amostra, quando comparada às demais. Já a utilização isolada do aditivo lactato de sódio (F1) evidenciou ser mais eficaz contra as bactérias mesófilas, quando comparado às demais bactérias. Em relação às análises físico-químicas, observou-se boa estabilidade ao $\mathrm{pH}$ e diminuição da Aa. Porém, a amostra que continha apenas nisina
(F2), não manifestou aumento da validade comercial, evidenciando um comportamento similar à amostra Controle (sem aditivo).

\section{REFERÊNCIAS}

APHA (AMERICAN PUBLIC HEALTH ASSOCIATION). Compendium of methods for the microbiological examination of foods. 4.ed. Washington, 2001. 357-380p.

BRADLEY, E.M. et al. Effects of sodium lactate and acetic acid derivatives on the quality and sensory characteristics of hot-boned pork sausage patties. Meat Science, v.88, n.1, p.145-150, 2011. Disponível em: <http://www.sciencedirect.com/science/article/pii/ S030917 4010004456>. Acesso em: 05 mar. 2013. doi: 10.1016/j. meatsci.2010.12.015

BRASIL. Ministério da Agricultura. Secretaria Nacional de Defesa Agropecuária. Laboratório Nacional de Referência Animal. Métodos analíticos oficiais para controle de produtos de origem animal e seus ingredientes: II - Métodos físicos e químicos. Carne bovina "in natura”. Diário Oficial [da] República Federativa do Brasil, Cap.1, p.2, 1981.

BRASIL. Ministério da Agricultura, Pecuária e Abastecimento. Instrução Normativa $n^{\circ} 20$ de 21 de julho de 1999. Métodos analíticos oficiais para controle de produtos de origem animal e seus ingredientes. Diário Oficial [da] República Federativa do Brasil, p.10, 27 jul. 1999, Seção 1.

BRASIL. Ministério da Agricultura, Pecuária e Abastecimento. Instrução Normativa $n^{\circ}$ 62, de 26 de agosto de 2003. Aprova os métodos analíticos oficiais para análises microbiológicas para controle de produtos de origem animal e água. Diário Oficial [da] República Federativa do Brasil, p.14, 18 set. 2003, Seção 1.

BRASIL. Ministério da Agricultura, Pecuária e Abastecimento. Estatística de suíno. Disponível em: <http://www.agricultura. gov.br/animal/especies/suinos>. Acesso em: 20 jul. 2013.

BUNCIC, S. et al. Individual and combined listericidal effects of sodium lactate, potassium sorbate, nisin and curing salts at refrigeration temperature. Journal of Food Safety, v.15, n.3, p.247-264, 1995. Disponível em: <http://onlinelibrary.wiley.com/ 
doi/10.1111/j.17454565 .1995.tb00137.x/abstract>. Acesso em: 05 mar. 2013. doi: 10.1111/j.1745-4565.1995.tb00137.x.

DEEGAN, L.H. et al. Bacteriocins: biological tools for bio-preservation and shelf-life extension. International Dairy Journal, v.16, p.10581071, 2006. Disponível em: <http://www.sciencedirect.com/science/ article/pii/S0958694605002827>. Acesso em: 06 mar. 2013. doi: 10.1016/j.idairyj.2005.10.026

DELVES-BROUGHTON, J. Nisin as a food preservative. Food Australia, v.57, p.525-527, 2005. Disponível em: <http://www. refdoc.fr/Detailnotice?cpsidt=17367047\&traduire=en $>$. Acesso em: 05 mar. 2013. doi: 10.1007/BF00399424.

HOUTSMA, P.C. et al. Minimum inhibitory concentration of sodium lactate for pathogens and spoilage organisms occurring in meat products. International journal of Food Microbiology, v.20, n.4, p.247-257, 1993. Disponível em: <http://www. sciencedirect.com/ science/article /pii/016816059390169H>. Acesso em: 06 mar. 2013. doi: 10.1016/0168-1605(93)90169-H

\section{ICMSF (INTERNATIONAL COMMISSION ON} MICROBIOLOGICAL SPECIFICATIONS FOR FOODS). Microorganisms in foods: application of hazard analysis critical point (HACCP) system to ensure microbiological safety and quality. Oxford: Blackwell, v.4. 1988. 357p.

JAY, M.J. Microbiologia de alimentos. 6.ed. Porto Alegre: Artmed, 2005. 711p.

LIN, K.W.; LIN, S.N. Effects of sodium lactate and trisodium phosphate on the physicochemical properties and shelf life of low-fat Chinese-style sausage. Meat Science, v.60, p.147-154, 2002. Disponível em: <http:/ www.sciencedirect.com/science/article/pii/S0309174001001164>. Acesso em: 05 mar. 2013. doi: 10.1016/S0309-1740(01)00116-4.

MACA, J.V. et al. Sodium lactate and storage temperature effects on shelf life of vacuum package beef top rounds. Meat Science, v.53, p.23-29, 1999. Disponível em: <http://www.sciencedirect. com/science/article/pii/S0309174099000327>. Acesso em: 05 mar. 2013. doi: 10.1016/S0309-1740(99)00032-7.

MILANI, L.I.G. et al. Bioproteção de linguiça de frango. Ciência e Tecnologia de Alimentos, v.23, p.161-166, 2003. Disponível em: <http://www.scielo.br/scielo.php?script =sci_arttext\&pid=S0 10120612003000200010\&lng $=\mathrm{en}>$. Acesso em: 04 mar. 2013. doi: 10.1590/S0101-20612003000200010.
NYKANEN, A. et al. Synergistic inhibition of Listeria monocytogenes on cold-smoked rainbow trout by nisin and sodium lactate. International of Journal of Food Microbiology, v.61, n.1, p.63-72, 2000. Disponível em: <http://www.sciencedirect. com/science/article /pii/S0168160500003688>. Acesso em: 05 mar. 2013. doi: 10.1016/S0168-1605(00)00368-8

PAPADOPOULOS, V. et al. Effect of gutting on microbiological, chemical, and sensory properties of aquacultured sea bass (Dicentrarchus labrax) stored in ice. Food Microbiology, v.20, p.411-420, 2003. Disponível em: <http://www.sciencedirect.com/ science /article/pii/S074000200200148X>. Acesso em: 05 mar. 2013. doi: 10.1016/S0740-0020(02)00148-X.

SALLAM, K.H.I. Antimicrobial and antioxidant effects of sodium acetate, sodium lactate, and sodium citrate in refrigerated sliced salmon. Food Control, v.18, n.5, p.566-575, 2007. Disponível em: <http://www.sciencedirect.com/science/article/pii/ S0956713506000247>. Acesso em: 05 mar 2013. doi:10.1016/j. foodcont.2006.02.002

SAMELIS J. et al. Combinations of nisin with organic acids or salts to control Listeria monocytogenes on sliced pork Bologna stored at $4^{\circ} \mathrm{C}$ in vacuum packages. Food Science and Technology, v.38, p.21-28, 2005. Disponível em: <http://www.sciencedirect. com/ science/article/pii/S0023643804001124>. Acesso em: $04 \mathrm{mar}$ 2013. doi: 10.1016/j.lwt.2004.04.012..

TAN, W.; SHELEF, L.A. Effects of sodium chloride and lactates on chemical and microbiological changes in refrigerated and frozen fresh ground pork. Meat Science, v.62, p.27-32, 2002. Disponível em: <http://www.sciencedirect.com/science/ article/ pii/S0309174001002236>. Acesso em: 04 mar. 2013. doi: 10.1016/ S0309-1740(01)00223-6.

TARLADGIS, B.G. et al. distillation method for the quantitative determination of malonaldehyde in rancid foods. Journal of the American Oil Chemists' Society, v.37, p.44-48,1960. Disponível em: $<$ http://link.springer.com/article/10.1007/BF02630824>. Acesso em: 03 mart. 2013. doi: 10.1007/BF02630824.

WANG, F. S. Effects of three preservative agents on the shelf life of vacuum packaged Chinese-style sausage stored at $20^{\circ} \mathrm{C}$. Meat Science, v.56 p.67-71, 2000. Disponível em: <http://www. sciencedirect.com/science/article/pii/S030917400000022X $>$. Acesso em: 04 mar 2013. doi: 10.1016/S03091740(00)00022-X. 